\section{Eficacia y efectividad de las vacunas contra la influenza en adultos mayores}

Durante cuatro décadas se han empleado vacunas para reducir los síntomas de la influenza en los adultos mayores. En el año 2000, 40 de los 51 países desarrollados o en rápido desarrollo recomendaron vacunar a todas las personas de 60-65 años de edad o más y tres años después se aplicaron 290 millones de dosis de vacunas contra la influenza en todo el mundo. El principal objetivo de vacunar a las personas de mayor edad es reducir el riesgo de complicaciones en los grupos más vulnerables. Entre los adultos mayores se han identificado dos grupos de alta prioridad: las personas de 65 años o más y los que residen en asilos e instituciones para adultos mayores.

El propósito de este trabajo fue identificar y evaluar los estudios que comparan la eficacia y la efectividad de las vacunas contra la influenza en personas de 65 años o más. Este estudio forma parte de dos revisiones realizadas por el Centro Cochrane que abarcan también la seguridad de las vacunas estudiadas y su efectividad en el personal que presta servicios de salud.

Se buscaron los trabajos publicados sobre este tema antes del 31 de diciembre de 2004, independientemente del idioma, en cinco bases de datos electrónicas (Cochrane Library, MEDLINE, EMBASE, Biological Abstracts y Science Citation Index). Se encontraron 5 estudios aleatorizados, 49 de cohorte y 10 de casos y testigos que evaluaron la eficacia contra la influenza (reducción de casos confirmados por el laboratorio) o su efectividad contra enfermedades similares a la influenza (disminución de casos sintomáticos). De los 96 conjuntos de datos (64 estudios) evaluados, $48(50 \%)$ informaron acerca de la circulación del virus A/H3N2, $4(4 \%)$ del virus B, $1(1 \%)$ del virus $\mathrm{A} / \mathrm{H} 1 \mathrm{~N} 1$, otro $(1 \%)$ del virus $\mathrm{A} /$ H2N2 y 7 (7\%) informaron acerca de la circulación de los virus $\mathrm{A} / \mathrm{H} 3 \mathrm{~N} 2$ y A/H1N1 simultáneamente. Los restantes 35 conjuntos de datos (37\%) no informaron acerca del subtipo de virus circulante.

La efectividad general de la vacuna fue significativa (23\%; intervalo de confianza de $95 \%$ [IC 95\%]: $6 \%$ a $36 \%$ ) cuando había una buena correlación entre la vacuna y la cepa circulante, pero no fue significativa cuando esa correlación era baja o se desconocía. No se encontró ninguna asociación (coeficiente de correlación: 0,09) entre la cobertura de vacunación y la tasa de ataque de enfermedades similares a la influenza.
La eficacia de la vacuna contra la influenza no fue significativa ( $R R=1,04$; IC 95\%: 0,43 a 2,51). Cuando las vacunas se correspondían con el serotipo circulante, presentaron una eficacia en la prevención de la neumonía de 46\% (IC 95\%: $30 \%$ a $58 \%$ ) y del ingreso hospitalario por influenza o neumonía de $45 \%$ (IC 95\%: $16 \%$ a $64 \%$ ), mientras que las vacunas con baja correspondencia con el serotipo circulante o de correspondencia desconocida no mostraron eficacia alguna.

Después de los ajustes por los factores de riesgo, las vacunas que tenían una buena correspondencia con las cepas circulantes redujeron el número de hospitalizaciones por influenza y neumonía $(\mathrm{EV}=$ 26\%; IC $95 \%$ : $12 \%$ a $38 \%$ ) y la mortalidad por todas las causas (EV $=42 \%$; IC 95\%: $24 \%$ a 55\%). Después del ajuste por los factores de confusión, la eficacia de dichas vacunas aumentó a 27\% (IC 95\%: 21 a 33) en el caso de los ingresos hospitalarios por influenza y neumonía, a 22\% (IC 95\%: 15 a 28) en el de las enfermedades respiratorias, a 24\% (IC 95\%: 18 a 30) en el de las enfermedades cardiovasculares y a 47\% (IC 95\%: 39 a 54) en la reducción de la mortalidad por todas las causas.

Estos resultados demuestran que la eficacia de la vacuna trivalente inactivada contra la influenza no es muy grande en personas de mayor edad, independientemente del lugar, la población y el diseño del estudio. La eficacia de la vacuna observada en la comunidad fue baja, independientemente de los ajustes realizados en función de las diferencias sistemáticas existentes entre las personas vacunadas y no vacunadas. (Jefferson $T$ et al. Efficacy and effectiveness of influenza vaccines in elderly people: a systematic review. Lancet. 2005;366(9492):1165-74).

\section{El narcofolclor en la frontera entre México y los Estados Unidos de América}

La llamada "guerra contra la droga", emprendida por el gobierno de los Estados Unidos de América, se basa en la idea de que el consumo y el tráfico de drogas constituyen actividades inequívocamente dañinas y peligrosas, temidas y rechazadas por la población. Sin embargo, en los grandes centros de tráfico de drogas, la economía relacionada con los estupefacientes es tan amplia y penetrante que se convierte en un componente "normal" de la vida cotidiana y el estigma que representa el 
tráfico de drogas es transformado y minimizado por las diferencias subculturales, las redes sociales y la omnipresente economía de la droga.

En los centros de tráfico de drogas situados en la frontera entre México y los Estados Unidos de América, como el formado por Ciudad Juárez y El Paso, el comercio ilegal de narcóticos se refleja en diversos elementos de su cultura expresiva- como la música, la ropa y las joyas- y en la manera en que viven las personas, en sus elegantes automóviles y ostentosas viviendas. Este artículo analiza el proceso de "normalización" del tráfico de drogas a fin de reducir el vacío que sobre este tema existe en la literatura especializada.

La normalidad con que se acepta el tráfico de drogas en la frontera mexicanoestadounidense se debe en parte a que esta es una de las regiones más pobres de los Estados Unidos y a que a lo largo de más de 100 años, esta actividad ha sido un medio práctico y rápido de aumentar los ingresos. Por lo tanto, el tráfico de drogas puede considerarse un medio que les permite a personas relativamente pobres salir de la pobreza y se ha convertido en parte de la identidad propia de muchas comunidades fronterizas.

A pesar de que los medios noticiosos de El Paso han reducido al mínimo la cobertura del narcotráfico, las personas que viven en esas localidades saben que el negocio ilícito de las drogas está a todo su alrededor. Las historias vinculadas con el tráfico de drogas a través de la frontera demuestran que los traficantes, como los drogadictos, "pueden ser víctimas, transgresores, hermanos, hermanas, hijos e hijas".

Las historias y canciones acerca de esta importante actividad económica y cultural forman una especie de cultura folclórica oral. Su representación popular más conocida corresponde a las canciones folclóricas denominadas "corridos", que recientemente han dado origen a los "narcocorridos", que narran las hazañas de famosos narcotraficantes mexicanos.

El folclor cotidiano también consiste en los cuentos "habituales" contados por algún participante, sus amigos o parientes. Dichos cuentos en torno a las drogas - como el folclor en general- benefician al narrador de diferentes formas: elevan su autoestima al permitirle impresionar a sus interlocutores con sus conocimientos y hazañas; ayuda a aligerar la carga de culpa y ansiedad que sufre y lo ayuda a divulgar una información encubierta sobre una actividad clandestina. Por lo general, estas historias tratan temas de iniciación, confesión, enfrentamiento, aleccionamiento $\mathrm{u}$ horror. Con frecuencia comienzan con el detenimiento de los protagonistas por la justicia y continúan con un recuento retrospectivo de los sucesos que condujeron a su captura.
El análisis de las costumbres y del folclor popular de la zona demuestra que para la población de la frontera mexicanoestadounidense, el tráfico de drogas es una actividad tácitamente tolerada o un fenómeno cotidiano que, sin ser totalmente aceptado, no se considera una desviación radical del estilo de vida imperante. Comprender este fenómeno puede ayudar a encaminar los esfuerzos por modificar las políticas contra el narcotráfico y los programas gubernamentales aplicados en la actualidad. (Campbell H. Drug trafficking stories: everyday forms of narco-folklore on the U.S.-Mexico border. Int J Drug Policy. 2005;16(5):326-33).

\section{Mayor respaldo científico para evaluar la eficacia de los programas de salud pública}

La Iniciativa Futuros (Futures Initiative), emprendida por los Centros para el Control y la Prevención de Enfermedades (CDC) de los Estados Unidos de América en 2003, impulsó la búsqueda de datos probatorios para evaluar la eficacia de los programas de salud pública relacionados con la misión de esos centros. Este trabajo evalúa las pruebas científicas publicadas sobre los factores de riesgo modificables y las intervenciones relacionados con las enfermedades que constituyen una mayor carga para la salud pública de los Estados Unidos y que son objeto de atención de los programas financiados por los CDC.

Se utilizaron ocho medidas de la carga de enfermedad, lesión y discapacidad (mortalidad, años de vida perdidos antes de los 75 años de edad, años de vida ajustados por discapacidad, causas de muerte, número de hospitalizaciones, días de hospitalización, casos de discapacidad y costos médicos directos) aportada por 20 enfermedades o combinaciones de enfermedades.

Se revisaron los trabajos publicados en PubMed, Morbidity and Mortality Weekly Report y el sitio en Internet de la Colaboración Cochrane. Se buscó información sobre los factores de riesgo modificables, la fracción atribuible (FA) o el porcentaje de riesgo atribuible poblacional (FAp), las intervenciones poblacionales dirigidas a la prevención primaria o secundaria de cada una de las enfermedades analizadas y la fracción prevenible (FPp).

En total se encontraron 682 publicaciones - de ellas 34 revisiones sistemáticas-, en las que se identificaron 194 factores de riesgo modificables asociados con las 31 enfermedades de mayor impacto sobre la salud que eran objeto de estudio de los CDC. Se identificaron 703 intervenciones de salud pública poblacionales relacionadas con $28(90,3 \%)$ de las 31 enfermedades estudiadas y con $139(71,6 \%)$ de los 194 factores de riesgo encontrados. Se halla- 